\title{
Gambling Disorder Symptoms, Suicidal Ideation, and Suicide Attempts
}

\author{
Kounseok Lee ${ }^{1 *}$, Hyesun $\mathrm{Kim}^{2}$, and YoungHo Kim ${ }^{3 凶}$ \\ ${ }^{1}$ Department of Psychiatry, Gangnam Eulji Hospital, Eulji University, Seoul, Republic of Korea \\ ${ }^{2}$ Department of Social Welfare, Kangwon National University, Chunchoeon, Republic of Korea \\ ${ }^{3}$ Department of Addiction Rehabilitation and Social Welfare, Eulji University, Seongnam, Republic of Korea
}

\begin{abstract}
Objective Gambling disorder (GD) patients have a higher suicide risk compared to the general population. The present study investigates the suicide-related risk factors of GD patients by analyzing GD diagnosis-related symptoms and suicide-related behaviors of subjects. Methods This study investigated which symptoms among GD diagnosis criteria are related to suicide risk in 142 patients diagnosed with GD. To analyze the relationship between GD symptoms and suicidal ideation and suicide attempt, the odds ratio (OR) was determined through multivariate logistic regression.

Results The number of symptoms was significantly higher in the subjects who had suicidal ideation group and attempt group. In the cases of past suicide attempts, responses to withdrawal and escape questions were significantly higher; in the cases of ongoing suicidal ideation, responses to negative consequences and bailout questions were significantly higher. When depression was corrected, the 'bailout' item was, indicating that 'bailout' increased suicidal ideation ( $\mathrm{OR}=4.937,95 \% \mathrm{CI}=1.009-24.164)$. In the suicide attempt group, 'relieve' item may increase suicide attempt ( $\mathrm{OR}=6.978,95 \% \mathrm{CI}=1.300-35.562)$.

Conclusion Past suicide attempts in GD patients correlated with withdrawal symptoms, and financial problem correlated with suicidal ideation. This suggests that evaluating suicide risk is important when evaluating GD patients, and evaluation of financial problems is important for GD patients with suicide risks.

Psychiatry Investig 2021;18(1):88-93
\end{abstract}

Key Words Gambling disorder, Suicide, Risk factor, DSM-5, Bailout.

\section{INTRODUCTION}

Gambling is defined as risking something of value in the hopes of obtaining something of greater value. ${ }^{1}$ Gambling disorder (GD) is a disease that requires treatment because it causes problems in the home and occupations. ${ }^{2}$

Gambling disorder is common and occurs worldwide and is culturally universal. ${ }^{3}$ In the USA, the lifetime prevalence of GD was approximately from $0.42 \%$ to $4.0 \%{ }^{3}$ In Korea, the oneyear prevalence rate of problem gambling or gambling disorder in the general population was $3.8 \%{ }^{4}$ The lifetime preva-

\footnotetext{
Received: January 28, 2020 Revised: August 26, 2020

Accepted: November 8, 2020

$\triangle$ Correspondence: YoungHo Kim, PhD

Department of Addiction Rehabilitation and Social Welfare, Eulji University, 553 Sanseong-daero, Sujeong-gu, Seongnam 13135, Republic of Korea Tel: +82-31-740-7475, Fax: +82-31-740-7389, E-mail: kyh1212@eulji.ac.kr

*Kounseok Lee was employed by Eulji University at the time that the work was conducted and his current affiliation is Hanyang University Medical Center.

(a) This is an Open Access article distributed under the terms of the Creative Commons Attribution Non-Commercial License (https://creativecommons.org/licenses/bync/4.0) which permits unrestricted non-commercial use, distribution, and reproduction in any medium, provided the original work is properly cited.
}

lence rates gambling disorder was approximately $0.5 \%{ }^{5}$

The Diagnostic and Statistical Manual of Mental DisordersFifth Edition (DSM-5) evaluates nine symptoms related to gambling and diagnoses GD by excluding manic episode. As the result of GD jeopardize or lose important relationships with family members or friends. In the evaluation process, the clinician can identify and use the addiction severity of the patient, motivation for change, insight into disease, and social support system to create treatment plans for patients. GD is often accompanied by legal and financial problems; thus, clinicians need to properly attend to $\mathrm{GD}^{2,6}$

The coexisting diseases of GD are one of the things that clinicians should identify in the evaluation step. GD is often accompanied by other additive diseases as coexisting diseases. Dowling et al. ${ }^{7}$ reported that GD can be accompanied by alcohol addiction at a rate of $21.2 \%$ of all GD patients and substance addiction at a rate of $7 \%$ of all GD patients. Alcohol or substance addictions occur in younger populations which may also lead to GD and may act as a risk factor for the onset of GD. ${ }^{8,9}$ Accompanying diseases/problems have been reported to have 
negative effects on the severity, cravings, and duration of gambling problems. ${ }^{9}$ Mood disorders also often accompany GD. ${ }^{10}$ In particular, major depressive disorder can accompany GD. It has also been reported that mood disorders precede gambling problems and influences the onset and continuation of GD. ${ }^{8}$ These coexisting diseases are risk factors for suicide. ${ }^{11,12}$

Suicide is a very complex human behavior. It has many meanings, and involves biological, mental, and social factors. Approximately $95 \%$ of all people who commit suicide or attempt to do so have a psychiatric disorder, and depression accounts for $80 \%$ of the psychiatric disorders. ${ }^{13-15}$ Substance-Related and Addictive Disorders independently increases the risk of suicidal behavior. ${ }^{16,17}$

In South Korea gambling is a crime under Chapter 23 of the Criminal Act. Exceptionally Kangwon Land operates for domestic customers under its gaming licenses. The suicide rate in Jeongseon, which covers Kangwon Land, is one of the highest cities in Gangwon Province. An average of 32.6 per 100,000 people took their own lives in 2016.

Primary depression is not common, depressive symptoms are a very common finding among GD patients. ${ }^{18}$ Also the GD increase the risk of suicidal ideation, suicide attempts, and suicide success. ${ }^{19}$ The GD group who suffers from mental pain due to addiction and resulting secondary problems are known to have a high ratio of suicidal impulses and suicide attempts. ${ }^{20-22}$ A comparative study on the suicide rates of cities with largescale casinos versus other cities found very high suicide rates among residents and visitors to the casino cities. Las Vegas was ranked with the highest suicide rates among residents and visitors. ${ }^{23}$ Furthermore, a survey of 162 Gamblers Anonymous (GA) members in the U.K. found that $77 \%$ of GD patients have thought about suicide and $20 \%$ of them have previously attempted suicide. ${ }^{24}$ College students with gambling problems have considered or attempted suicide twice more than other college students. ${ }^{25}$

Suicide is frequent in patients with GD. ${ }^{22,26,27}$ But there are no studies on what specific symptoms (by DSM- 5 diagnostic criteria) are associated with the suicide risk in GD patients. This study evaluates the suicide risk factors of GD patients by analyzing GD diagnosis-related symptoms and suicidal behaviors of subjects who visited treatment centers with the main problem of GD.

\section{METHODS}

\section{Participants}

The subjects of this study were recruited from patients in a gambling disorder treatment center in Gyeonggi Province. Patients were made to understand the purpose of study and were only enrolled in the study when they provided written con- sent to the utilization of the survey results for the research and treatment of gambling problems. The data of the 142 patients who completed the Problem Gambling Severity Index (PGSI) questionnaire and diagnosis survey among 172 visitors were analyzed. This study was approved by the Institutional Review Board of Eulji University (EUIRB2018-115).

\section{Measurements}

\section{Diagnostic criteria for GD}

The DSM-IV classifies pathological gambling as morbid gambling which is a subtype of impulse control disorder. The DSM-5 was revised in 2013 and deleted the eighth question, which was one of the diagnosis criteria. The present study followed the diagnosis criteria of GD based on the DSM- 5 criteria. Subjects were evaluated to suffer from GD when they satisfied at least four out of nine diagnosis criteria and they were declared to suffer from subclinical GD when they satisfied two or three criteria. The severity of GD was classified into three levels depending on how many criteria they satisfied (2-3 mild, 6-7 moderate, 8 $^{-9}$ severe).

\section{PGSI}

The PSGI is a measure of problem gambling consisting of nine items among 31 items of the Canadian Problem Gambling Index (CPGI), which was developed in Canada to measure the problem of GD. ${ }^{28}$ The PSGI evaluates problematic gambling behaviors and negative consequences over 12 months (Betting more than can afford to lose, Betting more for same excitement, Chasing losses, Borrowing money, Self-perception of gambling problems, Health problems, Criticized over gambling behavior, Financial problems, Feeling guilty about gambling). The PSGI is short, clear, easy to fill in, does not require training, and cost effective. Owing to these advantages, it is used in Canada, the U.K., Australia, and the U.S. as a prevalence survey, screening tool, and research tool. Based on the total score of the answers out of nine questions in total, the PSGI determines patients to be non-problem gamblers ( 0 point), low-risk gamblers (1-2 points), moderate-risk gamblers (3-7 points), and problem gamblers (8 points or higher). This study used the Korean version of PGSI, which has been validated. ${ }^{29}$

\section{Assessment of suicidal risk and depressive mood}

The suicidal risk was assessed using direct questions ('Are you thinking about suicide? Have you ever tried to commit suicide in the last month?'). Then, they were grouped according to their answers. Depressive mood was assessed in the last month of depressive mood. 


\section{Statistical analysis}

The group difference was analyzed using independent sample t-test and $\chi^{2}$ test. The correlations between factors affecting suicidal ideation and suicide attempt were examined using logistic regression. We used three models. The first is an unadjusted model, the second added past suicide attempts, and the last model additionally corrected depressive mood in the second model. The odds ratio (OR) values and $95 \%$ confidence interval (CI) of the group with suicidal ideation relative to the group with no suicidal ideation were determined. For statistical analysis, SPSS v25.0 (IBM Corp., Armonk, NY, USA) and R 3.6.1 (R Development Core Team, Vienna, Austria, http://www.R-project.org/) with qvalue package 2.16.0 were used. Every p value was bilateral, and statistical significance was defined as $p<0.05$. Analysis of false discovery rate (FDR) was applied to control for experiment-wise type I errors resulting from multiple comparisons by providing an adjusted overall q-value, with adjusted $\mathrm{p}$ values. ${ }^{30}$ The q-value< 0.05 was considered statistically significant.

\section{RESULTS}

Most subjects were male $(140,98.6 \%)$, and their average age was $33.32(\mathrm{SD}=10.15)$ years. Thirty-nine subjects $(27.5 \%)$ had suicidal ideation in the last month (Table 1), among them 7 had suicide attempt previously.

The comparison of the number of symptoms between groups depending on suicidal ideation revealed that the number of symptoms was significantly higher in the subjects who had suicidal ideation $(7.18 \pm 1.28)$ than in the other subjects (6.59 \pm $1.70, \mathrm{t}=2.227, \mathrm{p}=0.03)$. The number of symptoms according to past suicide attempts $(7.83 \pm 1.12)$ was higher in the subjects with histories of suicide attempt than in other subjects (6.65 \pm 1.61, $\mathrm{t}=2.476, \mathrm{p}=0.01$ ) (Table 2).

Table 1. Baseline characteristics of study participants $(\mathrm{N}=142)$

\begin{tabular}{lc}
\hline Sex & \\
Male & $140(98.6)$ \\
$\quad$ Female & $2(1.4)$ \\
Age & $33.32 \pm 10.145$ \\
Suicidal ideation (current) & $39(27.5)$ \\
Previous suicide attempt (lifetime) & $12(8.5)$ \\
Depressive mood (last month) & $52(36.6)$ \\
Any legal problem (current and previous) & $25(17.6)$ \\
Symptom severity by DSM-5 criteria & \\
$\quad$ Mild & $29(20.4)$ \\
$\quad$ Moderate & $61(43.0)$ \\
Severe & $48(33.8)$ \\
\hline
\end{tabular}

Values were presented as mean \pm SD or $\mathrm{N}(\%)$
Regarding questions in the DSM diagnosis criteria, questions 8 (impact on life) and 9 (bailouts) showed significant differences in the comparisons between the group with no suicidal ideation and the group with suicidal ideation. Regarding differences depending on past suicide attempts, Questions 4 (preoccupation) and 5 (relieve) were significantly higher in the group with suicide attempts. Question 4 (preoccupation) is deals with withdrawal and refers to nervousness, restlessness, and irritableness. Question 5 (relieve) is deals with escape and refers to gambling as an escape from problems or a bad mood. Question 8 (impact on life) refers to the negative consequences in interpersonal relationships and work, such as relationship damage, hazards and losses in family and social relationships, jobs, and studies. Question 9 (bailouts) is refers to the state in which the subjects asked for help due to financial problems. The number of symptoms was significantly higher in both the suicidal ideation group $(\mathrm{t}=2.227 \mathrm{p}=0.03)$ and the past suicide attempts group ( $\mathrm{t}=2.476, \mathrm{p}=0.01)$ (Table 3 ).

The number of subjects who experienced depressive mood in the last month was 24 (23.3\%) in the group with no suicidal ideation, but $28(71.8 \%)$ in the group with suicidal ideation. Thus, it was significantly higher in the group with suicidal ideation $\left(\chi^{2}=28.663, \mathrm{p}<0.001\right)$.

The logistic regression analysis results showed that when no correction was done, and the suicide risk increased in both questions 8 (impact of life) and 9 (bailouts). When depressive mood and past suicide attempts were both adjusted, the result was insignificant with the impact of life (OR=2.379, 95\% $\mathrm{CI}=0.451-11.902)$ (Table 4). However, it was still significant $(\mathrm{OR}=4.937,95 \% \mathrm{CI}=1.009-24.164)$ in the case of bailouts (Table 4). In the previous attempt group, question 5 was significant (OR=6.978, 95\% CI=1.300-35.562) (Table 5) in the mod-

Table 2. The frequency of gambling disorder diagnostic items according to suicidal ideation $(\mathrm{N}=142)$

\begin{tabular}{lccccc}
\hline & $\begin{array}{c}\text { No suicidal } \\
\text { ideation } \\
(\mathrm{N}=103)\end{array}$ & $\begin{array}{c}\text { With suicidal } \\
\text { ideation } \\
(\mathrm{N}=39)\end{array}$ & $\chi^{2}$ or t & $\mathrm{p}$ & $\mathrm{q}$ \\
\hline 1. Tolerance & $88(85.4)$ & $34(87.2)$ & 0.071 & 0.79 & 0.11 \\
2. Withdrawal & $59(57.3)$ & $20(51.3)$ & 0.413 & 0.52 & 0.09 \\
3. Control & $82(82.5)$ & $37(94.9)$ & 3.564 & 0.06 & 0.02 \\
4. Preoccupation & $46(44.7)$ & $21(53.8)$ & 0.958 & 0.33 & 0.07 \\
5. Relieve & $43(41.7)$ & $17(43.6)$ & 0.039 & 0.84 & 0.11 \\
6. Chasing & $98(95.1)$ & $39(100)$ & 1.962 & 0.16 & 0.05 \\
7. Lying & $98(95.1)$ & $38(97.4)$ & 0.367 & 0.55 & 0.09 \\
8. Impact on life & $82(79.6)$ & $39(94.9)$ & 4.853 & 0.03 & 0.02 \\
9. Bailouts & $80(77.7)$ & $37(94.9)$ & 5.771 & 0.02 & 0.02 \\
Number of & $6.59 \pm 1.70$ & $7.18 \pm 1.28$ & 2.227 & 0.03 & \\
symptoms & & & & & \\
\hline
\end{tabular}

$\mathrm{q}$-value $=$ adjusted $\mathrm{p}$ value for false discovery rate control 
Table 3. The frequency of gambling disorder diagnostic items according to previous suicide attempt $(\mathrm{N}=142)$

\begin{tabular}{lrcccc}
\hline \multicolumn{7}{c}{$\begin{array}{c}\text { No suicide } \\
\text { attempt } \\
(\mathrm{N}=130)\end{array}$} & $\begin{array}{c}\text { With previous } \\
\text { suicide attempt } \\
(\mathrm{N}=12)\end{array}$ & & & & \\
& $112(86.2)$ & $10(83.3)$ & 0.072 & 0.79 & 0.51 \\
\hline 1. Tolerance & $113(56.2)$ & $6(50.0)$ & 0.169 & 0.68 & 0.51 \\
2. Withdrawal & $10(84.6)$ & $12(100)$ & 2.149 & 0.14 & 0.18 \\
3. Control & $110(83.3)$ & 6.874 & $<0.01$ & 0.02 \\
4. Preoccupation & $57(43.8)$ & $10(83.5)$ & 9.066 & $<0.01$ & 0.02 \\
5. Relieve & $50(38.5)$ & $10(83.3)$ & & \\
6. Chasing & $125(96.2)$ & $12(100)$ & 0.478 & 0.49 & 0.42 \\
7. Lying & $124(95.4)$ & $12(100)$ & 0.578 & 0.45 & 0.42 \\
8. Impact on life & $107(82.3)$ & $12(100)$ & 2.533 & 0.11 & 0.18 \\
9. Bailouts & $107(82.3)$ & $10(83.3)$ & 0.008 & 0.93 & 0.54 \\
Number of & $6.65 \pm 1.61$ & $7.83 \pm 1.12$ & 2.476 & 0.01 & \\
symptoms & & & & & \\
\hline
\end{tabular}

Table 4. Adjusted ORs and 95\% Cls for suicide ideation

\begin{tabular}{lccc}
\hline & $\begin{array}{c}\text { Unadjusted OR } \\
(95 \% \mathrm{CI})\end{array}$ & Model 1 & Model 2 \\
\hline Impact on life & 4.681 & 4.019 & 2.379 \\
& $(1.030-21.284)$ & $(0.876-18.447)$ & $(0.475-11.902)$ \\
Bailouts & 5.263 & 4.615 & 4.937 \\
& $(1.166-23.744)$ & $(1.208-26.112)$ & $(1.009-24.164)$ \\
\hline
\end{tabular}

Model 1 adjusted for previous suicidal attempts, Model 2 adjusted for depressive mood, previous suicide attempt. OR: odds ratio, CI: confidence interval

Table 5. Adjusted ORs and 95\% Cls for suicide attempt

\begin{tabular}{lccc}
\hline & $\begin{array}{c}\text { Unadjusted OR } \\
(95 \% \mathrm{CI})\end{array}$ & Model 1 & Model 2 \\
\hline Preoccupation & 4.338 & 5.275 & 4.054 \\
& $(0.877-21.451)$ & $(1.007-27.643)$ & $(0.754-21.793)$ \\
Relieve & 5.812 & 7.836 & 6.978 \\
& $(1.183-28.545)$ & $(1.496-41.049)$ & $(1.300-35.562)$ \\
\hline
\end{tabular}

Model 1 adjusted for suicidal ideation, Model 2 adjusted for depressive mood, suicidal ideation. OR: odds ratio, CI: confidence interval

el 2 (adjusted for depressive mood and suicidal ideation).

\section{DISCUSSION}

The patients with GD tend to suicidal ideation and attempt rates much higher. ${ }^{20,26}$ And it is one of the most unwanted result. This study evaluated the suicide risk factors of GD patients by analyzing the relationship between GD diagnosis-related symptoms, suicidal ideation, and previous suicide attempt in the subjects who visited the treatment center with the main complaint of GD. Questions 8 (impact of life) and 9 (bailouts) showed differences depending on suicidal ideation and ques- tions 4 (preoccupation) and 5 (relieve) showed differences depending on suicide attempts. When depressive mood and past suicide attempts were corrected in the regression analysis results, bailouts were the factor that significantly increased suicide risk. This confirms that financial problems are directly related to suicide risk rather than the negative results of diagnosis.

The GD is chronic and deteriorating disease. ${ }^{31}$ It has 4 stages (winning phase, followed by losing phase, desperation phase, and hopeless phase). Fantasies of escape and thoughts of suicide are reported to be common during desperation phase. ${ }^{32}$ Question 4 (withdrawal) and 5 (relieve) were associated with past suicide attempts. Even if you consider depressive mood, we find out the 'relieve' symptom may be a major risk factor in GD with suicidal attempt group. In that group do often gambles when feeling distressed (e.g., helpless, guilty, anxious, depressed). This could be another reason for antidepressants or mood stabilizers may help for the GD patients. The result from this study indicate a potential direction for pharmacological research in the GD patients.

The signal of stop for gambling is running out of money. ${ }^{33}$ Withdrawal is a symptom related to the interruption of gambling, and when gambling stopped due to financial problems, it can be associated with suicide attempts. In a study on gambling-related suicides in Australia, comorbid depression, large financial debts, and relationship difficulties were presented as causes. ${ }^{26}$ Escapism from problems means to gamble to escape from emotional problems such as suffering. Thus, this can reflect the emotional state of GD patients. And it also correlated with desperation phase.

The number of symptoms relating to the past suicide attempt and suicidal ideation was significantly higher in the group with the symptoms. This corresponds with the result of a previous study which revealed the suicide rates were higher in patients who satisfied more GD diagnostic criteria of DSM-5. ${ }^{34}$ The severity is classified according to the number of DSM- 5 diagnosis criteria satisfied. Therefore, the more serious the symptoms are, the higher the suicide risk becomes.

Major adverse consequence due to an engagement with gambling that leads to break their personal and social relationship. ${ }^{35}$ Their suicide risk factors are including comorbid depression, large financial debts and relationship difficulties. ${ }^{26}$ In previous studies, the causes of suicide in GD are high impulsivity and the breakdown of relationships. ${ }^{36,37}$ Thwarted belongingness and perceived burdensomeness are factors that have the greatest effects on suicidal ideation and are causes of the desire to commit suicide. ${ }^{38} \mathrm{GD}$ patients think that suicide is a solution to their gambling problem. ${ }^{27}$ Furthermore, financial problems due to gambling are associated with increased conflict with families, which is associated with increased suicidal impulses. ${ }^{39}$ The results of this study show that financial problems had 
higher correlation with suicidal ideation than other problems for GD patients. This corresponds with the finding that when compared with gamblers with no suicidal ideation, the gamblers with suicidal ideation had more serious gambling problems, greater debts, and more legal problems. ${ }^{36}$

With respect to suicide, low social support is known to lead to vulnerability and depression. ${ }^{38}$ For GD patients, suicide is associated with their consciousness of themselves as a burden to other people due to financial problems and their conflict with people in their lives. Therefore, we can think of a series of processes leading to suicide, such as the occurrence of suicidal ideation due to financial problem, which leads to withdrawal, and then attempts to commit suicide. GD patients are known to have high accompaniment rates of mental diseases such as substance use disorders, depressive disorders, anxiety disorders, and personality disorders. ${ }^{1}$ This study found that financial problems are highly correlated with suicide risk even after correcting accompanied depressive symptoms, which are a main risk factor of suicide.

When assessing suicide risk, it is crucial to assess depressive symptoms. ${ }^{40}$ However, when assessing the suicide risk of GD patients, it is important to closely examine gambling symptoms and situations such as financial state and attitude toward family as well as depressive symptoms.

There are several treatment approaches to GD. The most commonly used ones are cognitive behavioral therapy and medications like opioid antagonists, glutaminergic drugs, and antidepressants. ${ }^{41}$ The treatments for GD are quite similar to the other addictive disorders. ${ }^{42}$ Still there is no specific treatment for suicidal risk in GD.

This study has a few limitations. First, the subjects are mostly male (140, 98.6\%). Second, the comorbidities of the subjects, especially bipolar disorder, could not be excluded. This is because data collected from counseling were analyzed instead of data from clinical practices. Furthermore, the depressive symptoms were based on questions about past experiences of depressive mood, and the questions did not evaluate the subjects' depression. Third, the temporal relation between gambling problems and suicidal risks could not be revealed. Most visitors came for counseling for gambling problems, and their problems can be estimated to be emotional problems resulting from gambling problems, but the possibility that prior mental problems caused by gambling problems could not be excluded. Therefore, more research on clinical patients evaluated through structured interviews will be necessary in the future. Fourth, suicidality was assessed by a simple question. In future study, it should be evaluated by a structured interview tool.

We have evaluated what symptoms are associated with the risk of suicide in GD patients. In our study clearly evaluated gambling disorder patients in accordance with the DSM-5 di- agnostic criteria and assessed their suicidal risks. This study is very meaningful because this study used real data of visitors in a treatment center with real problems instead of conducting an epidemiological study.

Past suicide attempts in GD are associated with withdrawal symptoms, and financial problems are associated with suicidal ideation. Withdrawal symptoms due to financial problems can increase suicide risk. This suggests that it is important to assess the suicide risk of GD patients in clinical practices and to assess the state of GD patients with suicide risk in need of help due to financial problems.

\section{Acknowledgments}

This paper was supported by Eulji University in 2018.

\section{Conflicts of Interest}

The authors have no potential conflicts of interest to disclose.

\section{Author Contributions}

Conceptualization: Kounseok Lee, YoungHo Kim. Data curation: YoungHo Kim, Kounseok Lee. Formal analysis: Kounseok Lee. Writingoriginal draft: Kounseok Lee. Writing—review \& editing: all authors.

\section{ORCID iDs}

$\begin{array}{ll}\text { Kounseok Lee } & \text { https://orcid.org/0000-0002-6084-5043 } \\ \text { Hyesun Kim } & \text { https://orcid.org/0000-0002-3316-0954 } \\ \text { YoungHo Kim } & \text { https://orcid.org/0000-0003-2273-7786 }\end{array}$

\section{REFERENCES}

1. American Psychiatric Association. Diagnostic and Statistical Manual of Mental Disorders (DSM-5 ${ }^{\circledR}$ ). Washington DC: American Psychiatric Publishing; 2013.

2. Dowling NA, Cowlishaw S, Jackson AC, Merkouris SS, Francis KL, Christensen DR. Prevalence of psychiatric co-morbidity in treatmentseeking problem gamblers: a systematic review and meta-analysis. Aust N Z J Psychiatry 2015;49:519-539.

3. Black DW, Shaw M. The Epidemiology of Gambling Disorder. In: Heinz A, Romanczuk-Seiferth N, Potenza M, Editors. Gambling Disorder: Switzerland: Springer, 2019, p.29-48.

4. Health NCfM. National Mental Health Statistics 2018. Seoul: National Center for Mental Health; 2020.

5. Kessler RC, Hwang I, LaBrie R, Petukhova M, Sampson NA, Winters $\mathrm{KC}$, et al. The prevalence and correlates of DSM-IV pathological gambling in the National Comorbidity Survey Replication. Psychol Med 2008;38:1351.

6. Mok JY, Choi SW. Clinical characteristics and assessment of pathological gambling. J Korean Acad Addict Psychiatry 2013;173-115.

7. Dowling NA, Merkouris SS, Lorains FK. Interventions for comorbid problem gambling and psychiatric disorders: advancing a developing field of research. Addict Behav 2016;58:21-30.

8. Kessler RC, Hwang I, LaBrie R, Petukhova M, Sampson NA, Winters $\mathrm{KC}$, et al. DSM-IV pathological gambling in the National Comorbidity Survey Replication. Psychol Med 2008;38:1351-1360.

9. Dowling NA, Merkouris SS, Greenwood CJ, Oldenhof E, Toumbourou JW, Youssef GJ. Early risk and protective factors for problem gambling: A systematic review and meta-analysis of longitudinal studies. Clin Psychol Rev 2017;51109-1124.

10. Dowling NA, Youssef GJ, Jackson AC, Pennay DW, Francis KL, Pennay $A$, et al. National estimates of Australian gambling prevalence: $f$ indings from a dual-frame omnibus survey. Addiction 2016;111:420- 
435

11. Karlsson A, Hakansson A. Gambling disorder, increased mortality, suicidality, and associated comorbidity: a longitudinal nationwide register study. J Behav Addict 2018;7:1091-1099.

12. Bischof A, Meyer C, Bischof G, John U, Wurst FM, Thon N, et al. Suicidal events among pathological gamblers: the role of comorbidity of axis I and axis II disorders. Psychiatry Res 2015;225:413-419.

13. Goldsmith SK, Pellmar TC, Kleinman AM, Bunney WE. Reducing Suicide: A National Imperative. Washington, DC: National Academies Press; 2002.

14. Hjelmeland H, Knizek BL. Suicide and mental disorders: a discourse of politics, power, and vested interests. Death Stud 2017;41:481-492.

15. Shahtahmasebi S. Examining the claim that $80-90 \%$ of suicide cases had depression. Front Public Health 2013;1:62.

16. Bohnert KM, Ilgen MA, Louzon S, McCarthy JF, Katz IR. Substance use disorders and the risk of suicide mortality among men and women in the US Veterans Health Administration. Addiction 2017;112:11931201.

17. Bischof A, Meyer C, Bischof G, John U, Wurst FM, Thon N, et al. Type of gambling as an independent risk factor for suicidal events in pathological gamblers. Psychol Addict Behav 2016;30:263-269.

18. Kim SW, Grant JE, Eckert ED, Faris PL, Hartman BK. Pathological gambling and mood disorders: clinical associations and treatment implications. J Affect Disord 2006;92:109-116.

19. Gupta R, Derevensky JL. Adolescents with gambling problems: from research to treatment. J Gambl Stud 2000;16:315-342.

20. Petry NM, Kiluk BD. Suicidal ideation and suicide attempts in treatment-seeking pathological gamblers. J Nerv Ment Dis 2002;190:462469.

21. Maccallum F, Blaszczynski A. Pathological gambling and suicidality: an analysis of severity and lethality. Suicide Life Threat Behav 2003;33: 88-98.

22. Battersby M, Tolchard B, Scurrah M, Thomas LJIjomh, addiction. Suicide ideation and behaviour in people with pathological gambling attending a treatment service. 2006;4:233-246.

23. Phillips DP, Welty WR, Smith MM. Elevated suicide levels associated with legalized gambling. Suicide Life Threat Behav 1997;27:373-378.

24. Moran E. Taking the final risk. Ment Health (Lond) 1969;28(Winter): 21-22.

25. Stuhldreher WL, Stuhldreher TJ, Forrest KYZ. Gambling as an emerging health problem on campus. J Am College Health 2007;56:75-83.

26. Blaszczynski A, Farrell E. A Case Series of 44 Completed GamblingRelated Suicides. J Gambl Stud 1998;14:93-109.

27. Sullivan S. Why compulsive gamblers are a high suicide risk. Community Mental Health in New Zealand 1994;8:40-47.
28. Ferris JA, Wynne HJ. The Canadian Problem Gambling Index: Canadian Centre on Substance Abuse. Ottawa, ON: Canadian Consortium for Gambling Research; 2001.

29. Kim AY, Cha JE, Kwon SJ, Lee SM. Construction and validation of Korean version of CPGI. Korean J Psychol Gen 2011;30:1011-1038.

30. Benjamini $Y$, Hochberg Y. Controlling the false discovery rate - a practical and powerful approach to multiple testing. J R Stat Soc Series B Stat Methodol 1995;57:289-300.

31. Custer RL. Profile of the pathological gambler. J Clin Psychiatry 1984; 45:35-38.

32. Lesieur HR, Rosenthal RJ. Pathological gambling: a review of the literature (prepared for the American Psychiatric Association task force on DSM-IV committee on disorders of impulse control not elsewhere classified). J Gambl Stud 1991;7:5-39.

33. Spada MM, Giustina L, Rolandi S, Fernie BA, Caselli G. Profiling Metacognition in Gambling Disorder. Behav Cogn Psychother 2015; 43:614-622.

34. Hodgins DC, Mansley C, Thygesen K. Risk factors for suicide ideation and attempts among pathological gamblers. Am J Addict 2006;15:303310.

35. Langham E, Thorne H, Browne M, Donaldson P, Rose J, Rockloff M. Understanding gambling related harm: a proposed definition, conceptual framework, and taxonomy of harms. BMC Public Health 2015; 16:80.

36. Frank ML, Lester D, Wexler A. Suicidal behavior among members of Gamblers Anonymous. J Gambl Stud 1991;7:249-254.

37. Blaszczynski A, Steel Z, McConaghy N. Impulsivity in pathological gambling: the antisocial impulsivist. Addiction 1997;92:75-87.

38. Joiner TE. Shyness and low social support as interactive diatheses, with loneliness as mediator: testing an interpersonal-personality view of vulnerability to depressive symptoms. J Abnorm Psychol 1997;106: 386-394.

39. Carr MM, Ellis JD, Ledgerwood DM. Suicidality among gambling helpline callers: a consideration of the role of financial stress and conflict. Am J Addict 2018;27:531-537.

40. Hawton K, Casanas ICC, Haw C, Saunders K. Risk factors for suicide in individuals with depression: a systematic review. J Affect Disord 2013;147:17-28.

41. Ginley MK, Rash CJ, Petry NM. Psychological Interventions in Gambling Disorder. In: Heinz A, Romanczuk-Seiferth N, Potenza MN, Editors. Gambling Disorder. Switzerland: Springer, 2019, p.181-194.

42. Pickering D, Keen B, Entwistle G, Blaszczynski A. Measuring treatment outcomes in gambling disorders: a systematic review. Addiction 2018;113:411-426. 